\title{
Planejamento e saúde: uma análise dos condicionantes socioambientais e institucionais para prevenção e controle do Aedes aegypti em Aracaju*
}

\section{Flavia Regina Sobral Feitosa ${ }^{1}$, Ivana Silva Sobral ${ }^{2}$, Maria do Socorro Ferreira da Silva ${ }^{3}$, Edilma Nunes de Jesus ${ }^{4}$, Haiane Pessoa da Silva ${ }^{5}$}

${ }^{1}$ CCBS/Odontologia. Universidade Federal de Sergipe/UFS. Mestre em Desenvolvimento e Meio Ambiente - PRODEMA. E-mail: flaviareginasf@gmail.com. ${ }^{2}$ Bacharelado e Licenciatura em Biologia. UFS. Doutora em Geografia - UFS. Pós-doutoranda PRODEMA/UFS.

${ }^{3}$ Doutora em Geografia. Professora adjunta DGE/UFS.

${ }^{4}$ Bacharelado e Licenciatura em Biologia/UNEB. Mestre em Agroecossistemas/UFS. Doutoranda em Desenvolvimento e Meio Ambiente - PRODEMA/UFS.

${ }^{5}$ DGE/Licenciatura em Geografia. Universidade Federal de Sergipe. Mestre em Desenvolvimento e Meio Ambiente - PRODEMA.

Resumo. O planejamento é um instrumento fundamental para assegurar um modelo de assistência integral, uma melhor gestão do Sistema Único de Saúde (SUS), entendimento dos processos de adoecimento e vulnerabilidades socioeconômicas, pois organizam as ações e serviços existentes na rede de assistência, dando resoluções às necessidades de saúde da população. Assim, o objetivo deste artigo é analisar os condicionantes socioambientais e institucionais que interferem na prevenção e controle do Aedes aegypti no Município de Aracaju-SE. Para tanto, foram realizadas revisões bibliográficas e análise dos documentos emitidos pela Secretaria de Saúde do município, a fim de compreender a proposta de modelo de atenção à saúde instituída pelo SUS para o controle das endemias disseminadas por esse vetor. Os resultados obtidos permitiram identificar as fragilidades institucionais e os principais problemas socioambientais para efetividade do programa de prevenção e controle do Aedes aegypti. Nesse sentido, acredita-se que políticas públicas, planejamento urbano e a sensibilização da população para ações de Educação Ambiental poderão contribuir de maneira significativa para melhor administração do território.

Palavras-chave: SUS; Rede de assistência; Educação Ambiental.

Abstract. Planning and health: an analysis of the social, environmental and institutional factors for prevention and control of Aedes aegypti in Aracaju. Planning is a key tool to ensure comprehensive care model, better management of the Unified Health System (SUS), understanding of disease processes and socioeconomic vulnerabilities by organizing existing activities and services in the service network, giving resolution to health needs of the population.
Recebido:

29/07/2016

Aceito:

29/09/2016

Publicado:

30/09/2016

Acesso Aberto Artigo completo

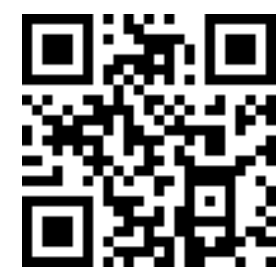

ORCID

(D) 0000-0001-9390-7020

Flavia Regina Sobral Feitosa

(D) 0000-0001-8259-2676 Ivana Silva Sobral

(D) 0000-0003-3656-5807

Maria do Socorro

Ferreira da Silva

(D) 0000-0002-4201-1213

Edilma Nunes de Jesus

*Apresentado no V Congresso Brasileiro de Educação Ambiental Aplicada e Gestão Territorial, Fortaleza/CE, 8 a 11/06/2016. 
The objective of this article is to analyze the social, environmental and institutional factors that interfere with the prevention and control of Aedes aegypti in the Municipality of Aracaju-SE. Therefore, reviews and analysis of documents issued by the county Health Department were conducted in order to understand the proposed health care model established by SUS for the control of endemic diseases spread by this vector. The results allowed to identify institutional weaknesses and the main environmental problems effectiveness of the prevention program and control of Aedes aegypti. In this sense, it is believed that public policy, urban planning and public awareness for environmental education activities could contribute significantly to better administration of the territory.

Keywords: Unified Health System - SUS; Assistance network; Environmental Education.

\section{Introdução}

O Sistema Único de Saúde é o modelo de cuidado trazido pela Constituição Federal de 1988 e possui como princípios doutrinários basilares a acessibilidade, universalização, a integralidade, a equidade e a participação social. Estes, para serem concretizados, precisam ser alicerçados nas diretrizes da descentralização, fragmentação e ordenação territorial (Brasil, 2005).

Dessa forma, a saúde precisa ser concebida em sua acepção ampla, tendo sua rede de assistência organizada a partir dos condicionantes e potencialidades do território, pois só assim irá assegurar um modelo de cuidado que priorize a assistência coletiva sobre a individual, evitando o adoecimento físico e mental da população (Minayo, 2009).

A nossa Carta Magna reforça a saúde como um direito coletivo essencial, não podendo assim ser visualizado apenas como a ausência de doença, ou de uma patologia instalada, mas aproximando-a da noção de qualidade de vida, ou seja, como um estado de completo bem-estar físico, mental e social. Assim, Philippi Jr. e Pelicione (2006, p. 71) asseveram que [...] "a saúde pública deve ser compreendida como a ciência e a arte de promover, proteger e recuperar a saúde por meio de medidas de alcance coletivo e de motivação populacional".

Portanto, a concepção de saúde proposta pelo Sistema Único de Saúde
(SUS) fornece mecanismos legais para que as ações de assistência assegurem um modelo de atenção integral, pautado na sustentabilidade. E, isso só é possível por meio de práticas de promoção à saúde que integrem o homem ao ambiente, observando os condicionantes territoriais que interferem no processo de adoecimento, como: ocupação desordenada do solo, infraestrutura inadequada, saneamento básico precário, condições socioeconômicas deficitárias, entre outros (Nogueira et al., 2012).

Sendo assim, o grande desafio da saúde é a busca pela sustentabilidade socioambiental, uma vez que a estratégias da Vigilância Ambiental em Saúde não tem conseguido na prática alcançar a finalidade idealizada (agir antes que as nocividades à saúde acontecem), pois as estratégias adotadas não foram elaboradas a partir do diagnóstico do território e nem com a sensibilização e participação da comunidade (Minayo, 2009).

Desta forma, doenças como as transmitidas pelo mosquito Aedes aegypti (dengue, zika e chinkugunya) possuem uma estreita relação com a produção desigual dos espaços urbanos, já que a falta de planejamento territorial gera condições propiciais ao surgimento de criadouros e a uma maior predisposição para disseminação de diferentes sorotipos do Aedes aegypti, aumentando as chances de aparecimento da forma mais agressiva da doença (Pignatti, 2004). 
Isso ocorre porque o mosquito se adapta facilmente ao ambiente doméstico e peridomiciliar, encontrando habitats propícios para a sua reprodução e disseminação, já que nesses locais encontram recipientes ou materiais descartáveis que acumulam água (Silva e Nobrega, 2012). Sendo assim, este estudo tem o objetivo de analisar os condicionantes socioambientais e institucionais que interferem na prevenção e controle do Aedes aegypti, a luz da territorialização proposta pelo modelo de atenção à saúde instituída pelo SUS.

\section{Referencial teórico}

A epidemiologia apropriou-se dos conceitos de território e rede propostos pela geografia para pensar estratégias mais efetivas de controle das doenças e das vulnerabilidades socioambientais. Posto que, a incorporação dos conhecimentos oferecidos por essas categorias geográficas permite compreender a complexa dinâmica social que propicia a disseminação de patologias e vetores, como o Aedes aegypti, no território (Santos, 2004).

É necessário reconhecer que existe uma estreita relação entre as condições de vida e a saúde, de maneira que as políticas públicas necessitam atuar sobre os determinantes sociais do processo saúdedoença. Dessa forma, os princípios da descentralização e regionalização, balizadores do modelo de atenção proposto pelo SUS, viabilizam a operacionalidade de uma rede de assistência que propõe o uso eficiente dos recursos públicos, polarizando o cuidado em diferentes níveis de complexidade e corresponsabilizando as três esferas do poder público (federal, estadual e municipal) pela assistência em saúde (Mendes, 2010).

Através da regionalização podem ser identificadas as prioridades de saúde e os serviços e equipamentos que, respeitando os limites municipais, irão "garantir o acesso dos cidadãos a todas as ações necessárias para a resolução de seus problemas de saúde, otimizando os recursos disponíveis” (Brasil, 2005, p. 9).
Assim, para melhor gestão do SUS e entendimento dos processos de adoecimento, o território da saúde foi dividido em regiões. Esta organização foi pensada para se construir "práticas de saúde voltadas ao chão concreto, lugar da vida cotidiana das pessoas" (Rigotto e Santos, 2011). Ou seja, é na territorialização que se dá o movimento, o fluxo dos saberes e práticas que são continuamente construídos e reconstruídos a partir das relações vivenciadas e no modo como as pessoas se apropriam do território.

O Sistema Único de Saúde (SUS) adota a concepção de rede, organizado por meio de horizontalidades, compostas por uma malha de equipamentos e serviços que se interconectam, a fim de garantir um cuidado amplo, integral e equitativo. Assim, o controle de doenças epidêmicas deve ser assegurado por uma rede de promoção a saúde que além de "controlar a ocorrência de doenças, seu aumento e propagação, priorize as ações preventivas, democratizando as informações relevantes com o intuito da população conhecer seus direitos e os riscos de saúde a que estão expostos” (Silva, 2008, p. 70).

Mendes (2010) afirma que as redes assistenciais do SUS são canais que favorecem o enraizamento, a capilaridade, a cobertura e penetração do cuidado no território, servindo para operacionalizar os serviços e sistemas de saúde existentes.

A organização em rede é uma das estratégias adotadas para impulsionar o funcionamento do SUS. Optou-se por esse modelo de cuidado, em virtude das demandas serem complexas e necessitarem de um alto financiamento público, de maneira que um único ente administrativo e/ou serviço, agindo de forma isolada, não poderia arcar sozinho com um cuidado pautado na integralidade (Mendes, 2010).

O SUS tomou como eixo ordenador da sua rede de cuidado a Atenção Primária, em que as equipes de saúde da família são responsáveis pelo acompanhamento de uma população adstrita, de uma área predeterminada e se encarregam de direcionar o caminho dos usuários nos equipamentos e serviços disponíveis (Albuquerque e Stotz, 2004). 
Assim, mesmo integrando uma teia de relações, o trabalho da Vigilância Epidemiológica parte da apropriação do microterritório para mapear e diagnosticar as vulnerabilidades locais, pois 0 conhecimento dos condicionantes de adoecimento da população é primordial para elaborar o planejamento das ações de prevenção e controle de endemias (Catão e Guimarães, 2011).

Nesta perspectiva, buscam-se alcançar nas práticas de Vigilância em Saúde uma concepção de espaço relacional que supere a visão estática e biológica do adoecimento, com mecanismos que permitam a compreensão da historicidade, da dinâmica social, econômica, política e cultural da população, a fim de se atingir estratégias mais completas de cuidado em saúde (Faria e Bortolozzi, 2009).

\section{Metodologia}

O trabalho foi realizado na cidade de Aracaju/SE, situada na região Nordeste do Brasil. A Capital Sergipana possui uma extensão territorial de 181,857 km², ocupando $0,83 \%$ da área total do Estado. Seu clima tropical quente úmido, com temperatura média de $26^{\circ} \mathrm{C}$, pluviosidade anual por volta de $1.590 \mathrm{~mm}$ (IBGE, 2010), fornece condições propícias à disseminação do Aedes aegypti.

O Município de Aracaju tem 571.149 habitantes e uma alta densidade demográfica com 3140,65 hab $/ \mathrm{km}^{2}$, correspondendo a $28 \%$ de toda população de Sergipe (IBGE, 2010). Possui 40 bairros, quatro distritos, oito regiões de saúde, 43 Unidades de Saúde da Família, 187 Agentes de Combate às Endemias - ACEs

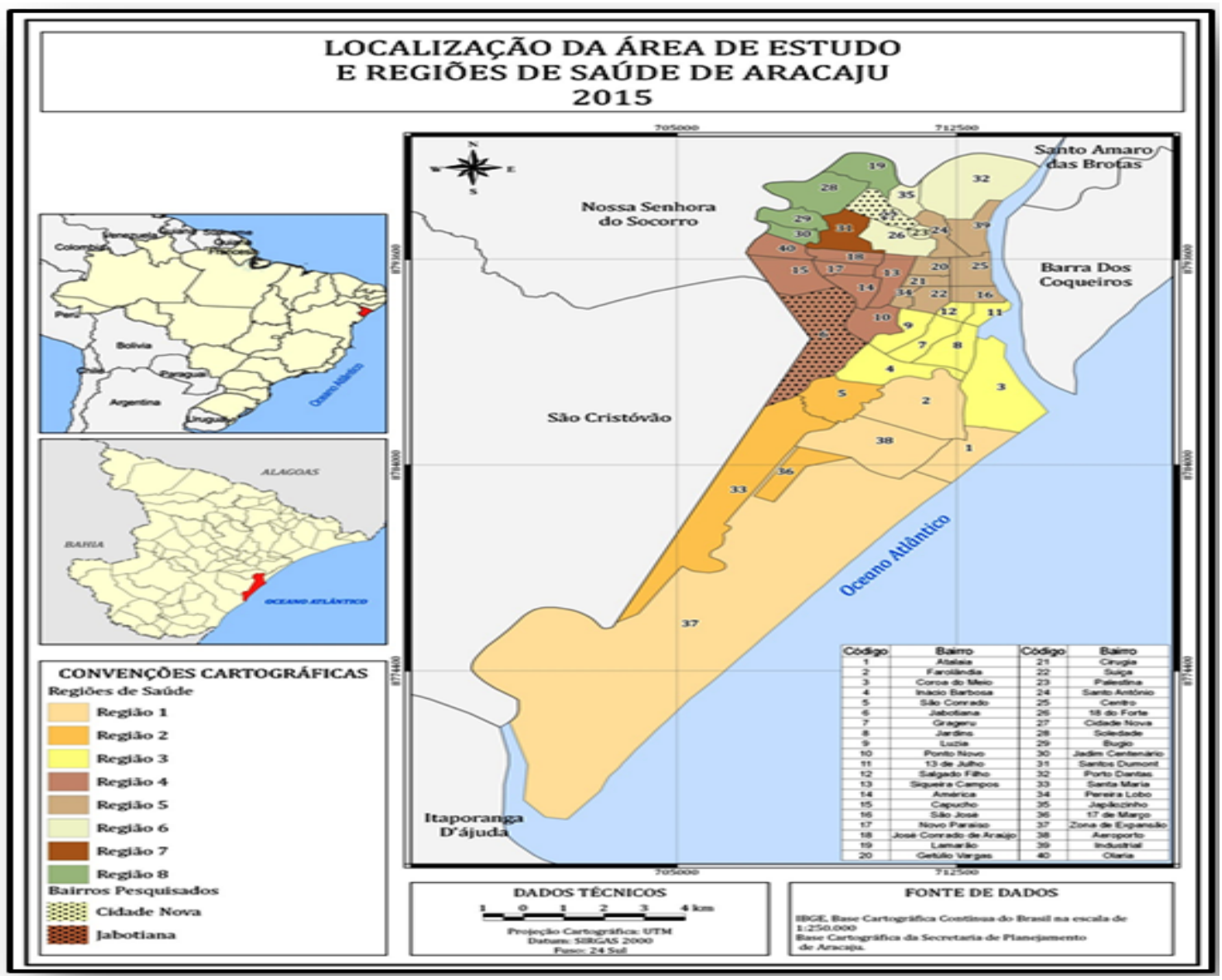

Figura 1. Mapa de Localização de Aracaju-SE, em 2015, com suas regiões de saúde. Fonte: Secretaria de Planejamento de Aracaju-SE (SEPLAN), 2015. 
(Figura 1), totalizando um percentual de 97,43\% da cidade assistida pela Estratégia de Saúde da Família (SMS, 2014).

Trata-se de um estudo descritivo, de natureza qualitativa, realizado por meio de revisão bibliográfica e documental relacionada ao tema proposto. Assim, a partir dos dados coletados acerca do ordenamento territorial e da dinâmica de proliferação do Aedes aegypti compreendeu-se como a Vigilância Epidemiológica, dentro do modelo proposto pelo SUS, organiza-se para tornar efetivas as estratégias de controle desse vetor.

\section{Resultados e discussões}

No Município de Aracaju, o processo de descentralização e municipalização possibilitou a aproximação do planejamento urbano e a execução local, articulando a vigilância epidemiológica com vários serviços dentro e fora do setor da saúde, a exemplo da Vigilância Sanitária, Rede de Urgência e Emergência e Atenção Primária, o que trouxe avanços nas estratégias municipais de enfretamento das doenças disseminadas pelo Aedes aegypti (Aracaju, 2008).

Nesse sentido, a proposta da política local é estreitar os laços da Vigilância Epidemiológica com a Atenção Primária (através da Estratégia de Saúde da Família-ESF), pois é nessa seara que são realizadas as ações de "notificação, imunização, diagnóstico, direcionamento da população para os equipamentos e dispositivos da rede de cuidado, tratamento precoce dos agravos e busca ativa" (Oliveira, 2004, p. 67).

Assim, compete ao Programa Municipal de Controle da Dengue realizar a pesquisa de criadouros e larvas para o levantamento de índice predial, reduzir a infestação e o número de casos de dengue, implantar ações de educação em saúde ambiental, detectar precocemente a circulação viral, além de adotar medidas de bloqueio adequadas para interromper a transmissão. E, para cumprir todas essas atribuições, este programa conta com o seguinte corpo funcional: um coordenação municipal, um coordenador geral de campo, oito supervisores gerais de região, 36 supervisores de campo, 202 agentes de combate às endemias (ACE), um agente de endemias responsável pela coleta de pneus, duas visitadoras que trabalham nas investigações de casos, e por fim, uma digitadora do Sistema de Informação do Programa Nacional de Controle da Dengue - SisPNCD (Aracaju, 2014).

Os Agentes de Combate às Endemias (ACEs) estão presentes em todos os bairros da Capital e seu quantitativo é delineado de acordo com o número de imóveis trabalhados em cada estrato, ou seja, para cada 800-1.000, é necessária a contratação de um profissional dessa categoria. Sendo que cada equipe de agentes, por questões logísticas e operacionais, é coordenada por um supervisor de campo que tem como atribuição distribuir e organizar o trabalho a ser executado no bairro. Ressalta-se ainda que, a cada cinco bairros tem-se um supervisor geral a quem cabe 0 planejamento das ações voltadas à prevenção e controle da dengue por região de saúde (Aracaju, 2014).

Os ACEs possuem como atribuições a realização de visitas a imóveis domiciliares, vistorias em estabelecimentos comerciais, terrenos baldios, pontos estratégicos, controle químico, mecânico e educação em saúde, no intuito de evitar a proliferação do Aedes aegypti. Sendo responsáveis também pelo registro dos mapas diários do Sistema de Informação da Febre Amarela e Dengue - SISFAD (Aracaju, 2002; Aracaju, 2008).

Para maior eficácia do trabalho de campo, os ACEs utilizam das estratégias de ordenamento e planejamento territorial, a exemplo do mapeamento das regiões em micro áreas que serão subdivididas em lotes, a fim de que esses profissionais cubram todo o território com suas visitas de rotinas, educação em saúde, identificação e eliminação dos focos de larvas e mosquitos (aracaju, 2002; Aracaju, 2008).

Nesse contexto, o município de Aracaju em 2014 possuía 256.291 imóveis, distribuídos em terrenos baldios (TB), moradias e outras categorias como pontos estratégicos, comerciais, igrejas, escolas 
(Tabela 1). Os pontos estratégicos (PE), apesar não terem sido vistoriados durante a coleta do LIRAa, são estabelecimentos que merecem um cuidado especial do PMCD, pois, pelas características físicas e atividades do estabelecimento, são locais que favorecem o surgimento e permanência da proliferação do Aedes, a exemplo dos cemitérios, ferro-velho, materiais de construção, borracharias, rodoviárias e transportadoras. E justamente, por essas peculiaridades que esses imóveis são trabalhados quinzenalmente, seguindo a padronização do PNCD (Aracaju, 2014).

Com isso, fica claro que as estratégias de gestão, prevenção e controle da dengue em nível municipal visam a identificar as potencialidades e fragilidades desse espaço e reduzir as áreas de maior vulnerabilidade de infestação pelo Aedes aegypti. E, isto só é possível através de um estreito contato da Vigilância Epidemiológica com a Rede de Atenção Primária (REAP), que é vinculada a Diretoria de Atenção à Saúde.

Embora a descentralização das ações do Programa Municipal de Controle da Dengue (PMCD) capilarize a atuação no microterritório, a Rede de Atenção Primária (REAP) e a Vigilância Epidemiológica (VE) são vinculadas a diretorias e gestores diferentes, o que dificulta o planejamento das ações de saúde de modo conjunto e integrado. Acredita-se então que, os entrelaçamentos das atividades desses setores são primordiais para a efetividade do combate ao mosquito Aedes aegypti, devendo estar vinculados a mesma rede de atenção (Figura 2).

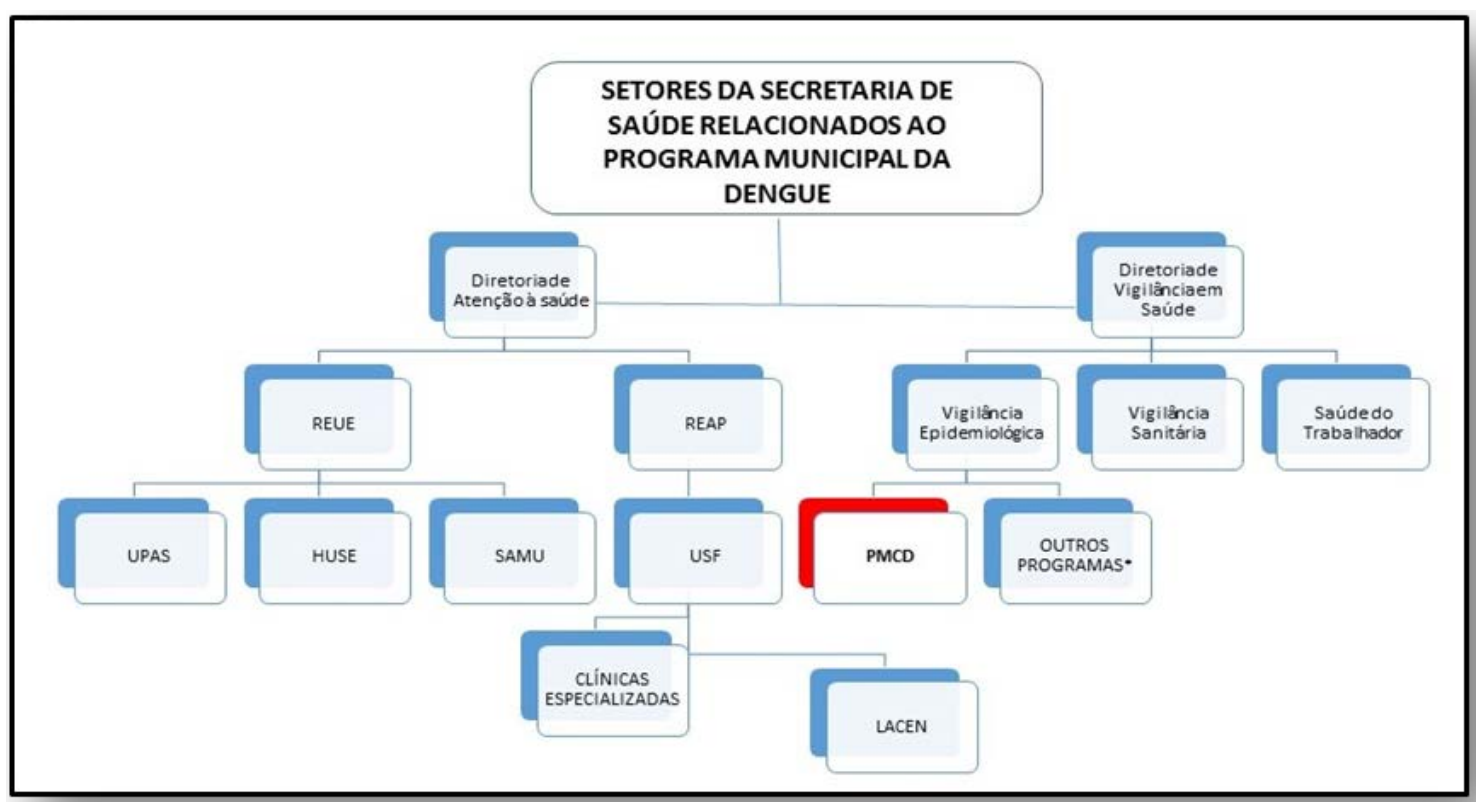

Figura 2. Organograma de funcionamento da Secretaria Municipal de Saúde de Aracaju-SE. Fonte: Secretaria Municipal de Saúde de Aracaju (2015). REUE - Rede Especializada de Urgência e Emergência; UPAS - Unidades de Pronto-Atendimento de Sergipe; HUSE - Hospital de Urgência de Sergipe; SAMU - Sistema Atendimento Móvel de Urgência; REAP - Rede Especializada de Atenção Primária; USF - Unidade de Saúde da Família; PMCD - Programa Municipal de Controle da Dengue.

\begin{abstract}
Desta forma, para consolidar o processo de descentralização, municipalização e tentar realizar um trabalho integrado entre essas redes, o Ministério da Saúde (MS) traz, em caráter opcional, a possibilidade da incorporação
\end{abstract}

dos ACEs na Atenção Primária à Saúde (APS), conforme define a Portaria GM $n^{\circ}$ $1.007 / 2010$.

No entanto, o Município de Aracaju não aderiu às diretrizes desse instrumento normativo, uma vez que os ACEs não são 
supervisionados pelos profissionais de nível superior da Estratégia de Saúde da Família (ESF) e nem vinculados administrativamente a esta rede (art. $1, \S 2^{\circ}$, Portaria GM $\mathrm{n}^{0}$ 1.007/2010). A adoção dessa estrutura reduziria os custos e quantitativos de profissionais (número de coordenadores de campo e de área) para a operacionalização do trabalho, possibilitando uma integração mais estreita com a Atenção Primária e o cumprimento das metas propostas pelo PNCD, pois doenças de cunho epidêmico como a dengue se incorporam ao espaço organizado pelo homem (Aracaju, 2008).

Assegurar uma rede horizontalizada e que atenda as metas da vigilância em saúde requer o funcionamento adequado dos equipamentos e serviços existentes, o que na prática não está ocorrendo frente a uma série de dificuldade operacionais.

$\mathrm{O}$ reduzido número de quantitativo de Agente de Combate às Endemias existentes na Secretaria Municipal de Saúde é um dos grandes obstáculos à operacionalização das ações de cuidado no território, pois embora o PNCD (2002) preconize que é necessário pelo menos 01 ACE para cada 800 a 1.000 imóveis, Aracaju possui somente 187 ACEs quando deveria ter 247, o que representa uma defasagem de 60 (sessenta) trabalhadores, já que o município possui aproximadamente 247.456 residências (Aracaju, 2015). Esse déficit dificulta o cumprimento das metas contempladas na Política Municipal de Controle da Dengue, uma vez que se estende o tempo para fechamento dos ciclos de visitas e realização dos indicadores de monitoramento, fragilizando as ações de Educação Ambiental realizada por esses técnicos (Vilani et al., 2009).

A intersetorialidade é outra fragilidade detectada no município, uma vez a parceria da Vigilância Epidemiológica com a Empresa Municipal de Serviços Urbanos (EMSURB) não está ocorrendo de maneira satisfatória, pois é comum reclamações da população de que a manutenção de vias e logradouros está deficitária, sendo recorrentes as denúncias na Secretaria de Saúde acerca da existência de locais públicos com acúmulo de água e lixo, conforme verificado nos registros de ouvidorias coletadas na secretaria municipal de saúde (Aracaju, 2015). E essas áreas alagadas e locais que abrigam restos de resíduos servem de habitats para a proliferação do Aedes aegypti.

A capital possui ainda um Plano Diretor desatualizado, estando a versão mais atual em processo de tramitação na Câmara de Vereadores. O plano em vigor, datado de 2000, pouco prioriza as áreas verdes de Aracaju. Isso tem se refletido no baixo índice de arborização da cidade, com $4 \mathrm{~m}^{2}$ de área verde por habitante, o que esta abaixo do recomendado pela Sociedade Brasileira de Arborização Urbana (Lima Neto et al., 2007). Isso faz com os vetores migrem de seu habitat natural para as áreas urbanas e peridomicílio em busca de melhores condições de proliferação.

Além disso, o crescimento urbano tem causado a diminuição da cobertura vegetal, do índice de áreas verdes, em detrimento ao surgimento de um solo exposto e/ou impermeabilizado pelo asfalto, o que dificulta o escoamento da água da chuva e favorece o acúmulo de lixo, facilitando assim a formação de criadouros do Aedes aegypti (Horta et al., 2013).

Embora Aracaju possua uma política de saneamento ambiental estruturada (coleta regular de resíduos sólidos, esgotamento sanitário e abastecimento água), em alguns bairros de vulnerabilidade socioeconômica como o Cidade Nova, Santa Maria, Porto Dantas, entre outros, a população ainda sofre com interrupção do abastecimento hídrico e com destinação inadequada de resíduos sólidos (nos logradouros, peridomicílio e terrenos baldios). Desta forma, é necessária a regulamentação pelo plano diretor dessas áreas que sofreram uma urbanização acelerada, sem serem devidamente acompanhadas do ordenamento territorial.

Neste contexto, o modo de uso e ocupação do solo possibilita compreender como o espaço geográfico se estrutura e funciona a partir dos seus elementos físicos, biológicos e socioeconômicos. $E$, ao se compartimentar essa paisagem (divisão em zonas) é possível delinear ferramentas para o planejamento e gestão racional dessas áreas (Petsch e Dal Santo, 2014). 
Rempel et al. (2009) compreende o zoneamento como a compartimentalização de uma região em porções territoriais que apresentam estrutura, funcionamento uniforme e alto grau de associação entre elas, mas com peculiaridades especificas e singulares de cada um desses compartimentos. A divisão em zonas é essencial para direcionar atividades econômicas e ações de proteção ambiental específicas para cada componente da paisagem, pois é realizado a partir do diagnóstico prévio da área, que inclusive pode sofrer transformações ao longo do tempo.

O atual Plano Diretor de Aracaju (2000), Lei Complementar $n^{\circ} 42 / 2000$, em seu artigo 128, incisos I, II e III, divide a capital em três grandes tipos de zonas de urbanização ou macrozonas agrupadas em função das características de uso e ocupação do solo, infraestrutura, padrão urbanístico e função social desses espaços. Estas se dividem em: Zonas de Adensamento Preferencial (ZAP's), Zonas de Adensamento Básico (ZAB's) e Zonas de Adensamento Restrito (ZAR) (Tabela 1).

Tabela 1. Tipos de zonas de urbanização do município de Aracaju em 2015.

\begin{tabular}{|c|c|c|}
\hline Macrozona & Legislação & Definição \\
\hline ZAP’s & Art. 130 e $131, \mathrm{LC} n^{\circ} 42 / 2000$ & $\begin{array}{l}\text { São zonas com maior potencial de urbanização, dada sua } \\
\text { disponibilidade da infraestrutura básica, equipamentos } \\
\text { urbanos e boa acessibilidade. Subdivide-se em ZAP 1, 2, 3, } \\
4 \text { e } 5 \text {. }\end{array}$ \\
\hline ZAB's & Art. 132 a 134, LC n²42/2000 & $\begin{array}{l}\text { São zonas com déficit de infraestrutura básica, sistema } \\
\text { viário e transporte. O adensamento e ocupação do solo deve } \\
\text { se dar de forma controlada. Divide-se em ZAB } 1 \text { e ZAB } 2\end{array}$ \\
\hline ZAR & Art. 135 e 136, LC n²42/2000 & $\begin{array}{l}\text { São zonas com padrão disperso e descontínuo, com } \\
\text { acentuado déficit de infraestrutura e serviços urbanos. } \\
\text { Atualmente conhecida como Zona de Expansão }\end{array}$ \\
\hline
\end{tabular}

Fonte: Plano Diretor de Aracaju, Lei Complementar nº 16/2000.

No entanto, esse zoneamento não contempla toda a Capital, pois nas ZABs ainda nota-se áreas com precário sistema de saneamento básico, devido ao crescimento desordenado e rápido desses espaços, existindo locais não regulados pelo Plano Diretor. Isto reforça a necessidade urgente de tornar efetivo o ordenamento territorial, para evitar que condições socioambientais favoreçam a disseminação de vetores e o adoecimento da população.

Assim, assegurar a qualidade da paisagem urbana é essencial à saúde da população, pois construções irregulares, ruas sem pavimentação, retirada da vegetação, ausência de saneamento básico, ocupação em áreas não recomendadas por risco de deslizamentos, falta de hospitais e escolas, desrespeito aos imóveis públicos que pouco funcionam aumentam a vulnerabilidade da população ao adoecimento (Santos, 2003).

Nesse sentido, o Estatuto da Cidade de Aracaju (Lei $n^{0}$ 10.257/2001), ao estabelecer nos artigos $2^{\circ}$ e $4^{\circ}$ a necessidade de se elaborar um Plano Diretor que faça um diagnóstico do território estudado, planejando-o por setores (zoneamento), a fim de se construir cidades sustentáveis que possuam um uso e ocupação do solo ordenado, reforça a importância desse instrumento para o saneamento ambiental (Brasil, 2001).

Outra dificuldade para consolidação da rede de prevenção e controle do Aedes aegypti em Aracaju é tornar efetiva a participação popular. Pois, embora existam campanhas educação ambiental, inclusive com a implantação do programa de coleta seletiva em alguns bairros da capital (Conjuntos Bela Vista, Santa Lúcia, Beira 
Mar I e II, Médici, J. K., Sol Nascente, Cirurgia, Getúlio Vargas, 13 de Julho, São José, Aeroporto, Jardins, Siqueira Campos, Grageru, Aruana e Inácio Barbosa, Loteamento Parque dos Coqueiros, Jardim Esperança e Beira Rio), a população não tem aderido satisfatoriamente essa iniciativa, eis que o volume de resíduos destinados a reciclagem ainda é muito pequeno (Aracaju, 2014).

Nesse sentido, mobilizar a população para adoção de hábitos sustentáveis é essencial para o planejamento e implementação de qualquer política pública, devendo a comunidade ser envolvida nesse processo, a fim de se obter estratégias mais efetivas de controle do vetor (Santos, 2004).

Santos e Pardo (2011) entendem a Educação Ambiental como um dos fatores primordiais para se alcançar a sustentabilidade, pois embora isoladamente ela não consiga equacionar os problemas ambientais, de maneira coletiva, interdisciplinar e interligada a diversos campos do conhecimento pode sensibilizar a comunidade para mudanças de práticas, valores, padrões de comportamento.

Portanto, a Educação Ambiental e a mobilização social são estratégias de sensibilização para mudanças de valores e atitudes importantes para o controle da infestação pelo Aedes aegypti, já que a efetividade dessas ações só será alcançada mediante estratégias continuadas e transversais que envolvam a gestão, trabalhadores e a comunidade.

\section{Considerações finais}

A rede de prevenção e controle ao Aedes aegypti no município de Aracaju, embora formalmente consolidada, apresenta uma série de obstáculos para tornar efetiva a assistência no modelo preconizado pelo SUS, dentre os quais podemos citar: o reduzido quantitativo de Agentes de Combate às Endemias e a frágil intersetorialidade entre os equipamentos e serviços de saúde. Além disso, o deficitário sistema de ordenamento territorial onde o atual plano diretor não contempla o uso e ocupação do solo de todas as áreas da capital e a precariedade do saneamento ambiental são fatores que contribuem para o surgimento e disseminação de criadouros do mosquito.

Desta forma, os condicionantes socioambientais e institucionais interferem na prevenção e controle do Aedes aegypti, uma vez que a distribuição espacial do vetor está associada apropriação desigual do espaço urbano e as fragilidades das estratégias de enfrentamento desse agravo. Sendo assim, é necessário incluir a participação da comunidade em todo o processo de implantação de políticas públicas, já que modelos integrados, efetivos e contextualizados só serão alcançados com a mobilização da comunidade.

Portanto, a Educação Ambiental é um instrumento capaz de promover o envolvimento comunitário, em razão da ação direta que exerce na percepção crítica dos atores sociais e nos processos educativos, contribuindo para uma maior "horizontalidade" no acesso às informações e estimulando o surgimento de novas possibilidades de compatibilização das práticas com os valores pautados na sustentabilidade.

\section{Declaração de conflito de interesses}

Os autores declaram não haver conflitos de interesses.

\section{Referências}

Albuquerque, P. C.; Stotz, E. N. A educação popular na atenção básica à saúde no município: em busca da integralidade. Revista Interface Comunicação, Saúde e Educação, v. 8, n. 15, p. 259-74, 2004.

Aracaju. Prefeitura Municipal. Plano Diretor de Desenvolvimento Urbano de Aracaju. Aracaju: SEPLAN, 2000.

Aracaju. Secretaria Municipal de Saúde. Informe da Vigilância Epidemiológica. Aracaju: SMS, 2013.

Aracaju. Secretaria Municipal de Saúde. Informe da Vigilância Epidemiológica. Aracaju: SMS, 2014. 
Aracaju. Secretaria Municipal de Saúde. Informe da Vigilância Epidemiológica. Sergipe, 2015.

Aracaju. Anteprojeto de Lei - Dispõe sobre a revisão do Plano Diretor de Desenvolvimento Urbano de Aracaju, e dá outras providências. Disponível em: <http://www.aracaju.se.gov.br/ userfiles/anteprojeto-de-lei-pddu.pdf $>$. Acesso em: 11 jan.2016.

Brasil. Lei no 10.257, de 10 de julho de 2001. Regulamenta os arts. 182 e 183 da Constituição Federal, estabelece diretrizes gerais da política urbana e dá outras providências. Disponível em: http://www.planalto.gov.br/ccivil_03/leis/LEIS_ 2001/L10257.htm>. Acesso em: 11 jan. 2016.

Brasil. Lei $\mathbf{n}^{\circ}$ 11.445, de 5 de janeiro de 2007. Disponível em: <http://www.planalto.gov.br/ ccivil_03/_ato2007-2010/2007/lei/l11445>.

Acesso em: 04 nov. 2014.

Brasil. Ministério da Saúde. Secretaria de Vigilância em Saúde. Diretoria Técnica de Gestão. Diagnóstico rápido nos municípios para a vigilância entomológica do Aedes aegypti no Brasil - LIRAa. Brasília: MS, 2005.

Brasil. Ministério da Saúde. Secretaria de Vigilância em Saúde. Diretoria Técnica de Gestão. Departamento de Vigilância Epidemiológica. Diretrizes nacionais para prevenção e controle de epidemia de dengue. Brasília: MS, 2009.

Catão, R. C.; Guimarães, R. B. Mapeamento da reemergência do dengue no Brasil - 1981/822008. Revista Brasileira de Geografia Médica e de Saúde. Hygeia, v. 7, n. 13, p. 173-185, 2011.

Faria, R. M.; Bortolozzi, A. Espaço, território e saúde: contribuições de Milton Santos para o tema da geografia da saúde no Brasil. Revista RAEGA, v. 1, n. 17, p.31-41, 2009.

Horta, M. A. P. Condicionantes socioambientais com influência da urbanização na transmissão de dengue: impactos à saúde pública. Rio de Janeiro: Fundação Oswaldo Cruz - Fiocruz., 2013. (Tese de doutorado).

IBGE - Instituto Brasileiro de Geografia e Estatística. Censo Populacional, 2010. Disponível em: <http://censo2010.ibge.gov.br/>. Acesso em: 04 fev. 2016.

Lima Neto, E. M; Resende, W. X; Melo e Souza, R. Áreas verdes públicas do Centro de Aracaju-SE: análise fitogeográfica. Revista da Fapese, v. 3, n. 2, p. 5-16, 2007.

Mendes, E. V. As redes de atenção à saúde. Belo Horizonte, 2010.
Minayo, M. C. S. Saúde e ambiente: uma relação necessária. In: Minayo, M. C. S.; Campos, G. W. S.; Akerman, M.; Drumond Júnior, M.; Carvalho, Y. M. (Org.). Tratado de Saúde Coletiva. São Paulo: Hucitec, 2009.

Nucci, J. C. Qualidade ambiental e adensamento urbano: um estudo de ecologia e planejamento da paisagem aplicado ao Distrito de Santa Cecília, MSP. São Paulo: Humanitas, FFLCH/USP, 2001.

Nogueira, M. G.; Souza, G. Oliveira; Rosário, L. A. S. Política pública de saúde e sustentabilidade socioambiental: gestão social frente à relação sociedade-natureza. Revista Sociedade em Debate, v. 18, n. 2, p. 41-53, 2012.

Oliveira, M. V. A. S. A educação popular em saúde e a prática dos agentes de controle das endemias de Camaragibe: uma ciranda que acaba de começar. Revista APS, v. 7, n. 2, p. 66-79, 2004.

Petsch, C.; Dal Santo, T. Qualidade da paisagem: função na gestão e planejamento através da determinação de compartimentos de paisagem no assentamento Tamarineiro I - MS. Revista Acta Geográfica, v. 7, n. 15, p. 153-163, 2014.

Philippi Júnior, A.; Pelicioni, M. C. F. Educação ambiental e sustentabilidade. Barueri: Manole, 2006.

Pignatti, M. G. Políticas ambientais e saúde: as Práticas sanitárias para o controle do dengue no ambiente urbano. Anais do II Encontro da ANPPAS, UFMT, Cuiabá, 2004.

PMCD - Programa Municipal de Controle da Dengue. Aracaju, 2008.

PNCD - Programa Nacional de Controle da Dengue. Brasília, 2002.

Rempel, C.; Guerra, T.; Porto, M. L.; Périco, E.; Eckhardt, R. R.; Cemin, G. A ecologia da paisagem como base para o zoneamento ambiental da Região Político-Administrativa Vale do Taquari-RS - Brasil: um modelo de proposta metodológica. GeoFocus, Jacupiranga, n. 9, p. 102-125, 2009.

Rigotto, R. M.; Santos, A. L. Território e territorialização: incorporando as relações de produção, trabalho, ambiente e saúde na atenção básica à saúde. Trabalho de Educação e Saúde, v. 8, n. 3, p. 387-406, 2011.

Santos, F. A S.; Pardo, M. B. L. O papel da escola e do educador para uma educação ambiental transformadora: a compreensão do conceito de Educação Ambiental dos professores de Indiaroba/SE. Anais do V 
Colóquio Internacional Educação e Contemporaneidade, São Cristóvão-SE, 2011.

Santos, R. F. Planejamento ambiental: teoria e prática. São Paulo: Oficina de Textos, 2004.

Santos, M. A natureza do espaço: técnica, razão e emoção. 4. ed. São Paulo: Editora da Universidade de São Paulo, 2004.

Santos, M. Saúde e ambiente no processo de desenvolvimento. Revista Ciências e Saúde Coletiva, São Paulo, v. 8, p. 309-314, 2003.

Silva, E. A. A epidemia da dengue: uma questão que envolve compromisso ético com a população. Revista Saúde Coletiva, v. 5, n. 21, p. 70, 2008.

Vilani, R. M; Machado, C. J. S; Rocha, E. T. S. Saneamento, dengue e demandas sociais na maior favela da Estado do Rio de Janeiro: a Rocinha. Revista Visa em Debate, v. 2, p. 163, 2009.

Informação da Licença: Este é um artigo Open Access distribuído sob os termos da Licença Creative Commons AtribuiçãoSemDerivações-SemDerivados, que permite o download do trabalho e o compartilhamento desde que seja atribuído o devido crédito, mas sem que possa ser alterado de nenhuma forma ou utilizá-los para fins comerciais. 